\title{
Experimental Investigation of the Wind Turbine Blade Root Flow
}

\author{
B. Akay ${ }^{*}$, C.S. Ferreira ${ }^{\dagger}$, G.J.W. van Bussel ${ }^{\ddagger}$ \\ Delft University of Technology, Delft, 2629 HS, Netherlands \\ G. Tescione ${ }^{\S}$ \\ Università degli Studi di Roma "La Sapienza", Rome, Italy
}

\begin{abstract}
Several methods from experimental to analytical are used to investigate the aerodynamics of a horizontal axis wind turbine. To understand 3D and rotational effects at the root region of a wind turbine blade, correct modeling of the flow field is essential. Aerodynamic models need to be validated by accurate experimental data. In this paper, the experimental results of the aerodynamic behavior of a model wind turbine blade, by focusing on the blade root flow, are presented. The measurements are performed on a 2 bladed rotor having $1 \mathrm{~m}$ radius by means of Stereo Particle Image Velocimetry in a wind tunnel. The spanwise velocity distribution on the suction side of the blade is determined in detail. It shows a complex flow pattern in the root region and positive spanwise flow component apparent at radial stations beyond $r / R=0.4$ at the leading edge $(z / c=0.25)$.
\end{abstract}

\section{Nomenclature}

$C_{p} \quad=$ power coefficient

$\lambda=$ tip speed ratio

$3 \mathrm{D}=$ three dimensional

OJF $\quad=$ open jet facility

PIV $=$ particle image velocimetry

\section{Introduction}

$\mathrm{T}$ HE amount of power produced in the inner part of the blade is small when compared with the power produced in the outboard part of the blade. Therefore, the design of the inner part of the blade is mainly based on structural considerations, which has resulted in an inboard section blade shape formed by a transition from a thick airfoil to a circular blade root connection.

The complexity of root flow renders it challenging for modeling; previous works focused on the hub area of the wind turbine blade reported different local $\mathrm{Cp}$ values on the inner part of the rotor depending on the aerodynamic model: BEM, Actuator Disk and 3D Navier Stokes and experimental methods ${ }^{[1],[2]}$.

Several phenomena drive the flow at the inboard part of the blade. Many studies show that at the root, where high angles of attack occur, the effect of the Coriolis and centrifugal forces is strong ${ }^{[3]}$. The influence of three dimensionality of a rotating blade on the laminar boundary layer which develops from the leading edge on its upper surface, in relation with the widely observed phenomenon of stall delay is investigated in ${ }^{[4]}$. It has been proved that the stall delay depends slightly on the reduced pressure effect and mainly on the accelerated boundary layer flow effects. To detect and identify pertinent aspects of the rotating boundary layer, both numerical and experimental

\footnotetext{
* PhD student, DUWIND, TUDelft, b.akay@ tudelft.nl, student.

${ }^{\dagger}$ Post-Doc. Researcher, DUWIND, TUDelft, C.J.SimaoFerreira@tudelft.nl.

*Proffessor, DUWIND, TUDelft, G.J.W.vanBussel@tudelft.nl.

${ }^{\S}$ MSc student, Engineering Faculty,Giuseppe.Tescione@gmail.com.
} 
research have been performed ${ }^{[5]}$; this work showed that in the regions where the boundary layer flow is $2 \mathrm{D}$ and generally moves along the chordwise direction, there is little to no rotational augmentation. Some studies ${ }^{[6], ~[7] ~}$ provided guidelines for developing an empirical approach that predicts post stall aerofoil characteristics and give insight about the aerodynamics of stall delay phenomena. Accurate predictions of 3D stall delay and dynamic stall characteristics are still the most challenging problems for aerodynamic analysis at the inboard section.

This paper presents some results obtained from the experiments which aim to measure the flow field around the wind turbine blade by focusing on the root region of the blade. The experimental investigations are carried out using Stereo Particle Image Velocimetry (Stereo PIV) in the Open Jet Facility at TUDelft.

\section{Experimental Set-Up and Results}

The experiments are performed in the Open Jet Facility (OJF) at the Faculty of Aerospace Engineering at Technical University of Delft (see Fig. 1). The maximum test section velocity is $30 \mathrm{~m} / \mathrm{s}$ and the octagonal jet has an equivalent diameter of $3 \mathrm{~m}$. A $1 \mathrm{~m}$ radius two-bladed rotor is used in the experiments. The twist and chord distribution obtained from BEM optimization are presented in Fig. 2. Lift distribution along the span which is computed by BEM is shown in Fig. 3. The DU-96 W 180 airfoil profile is used for the blade sections after $26.4 \%$ of the blade. The blade model has a $0.0643 \mathrm{~m}$ chord at the tip and $0.1079 \mathrm{~m}$ at the root and has a $16^{\circ}$ twist. It also has 2.5 times larger c/r distribution than that of the original wind turbine blade in order to increase the effect of stall delay at the root section of the model blade.

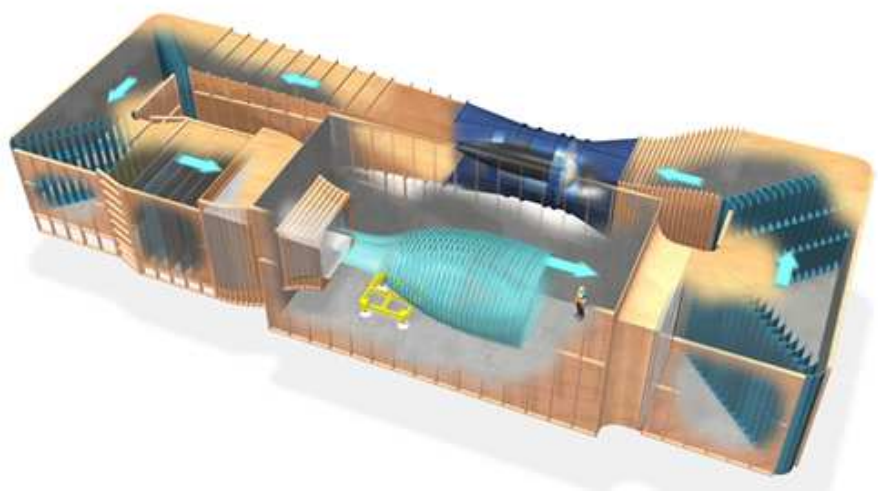

Figure 1 Schematic representation of OJF.
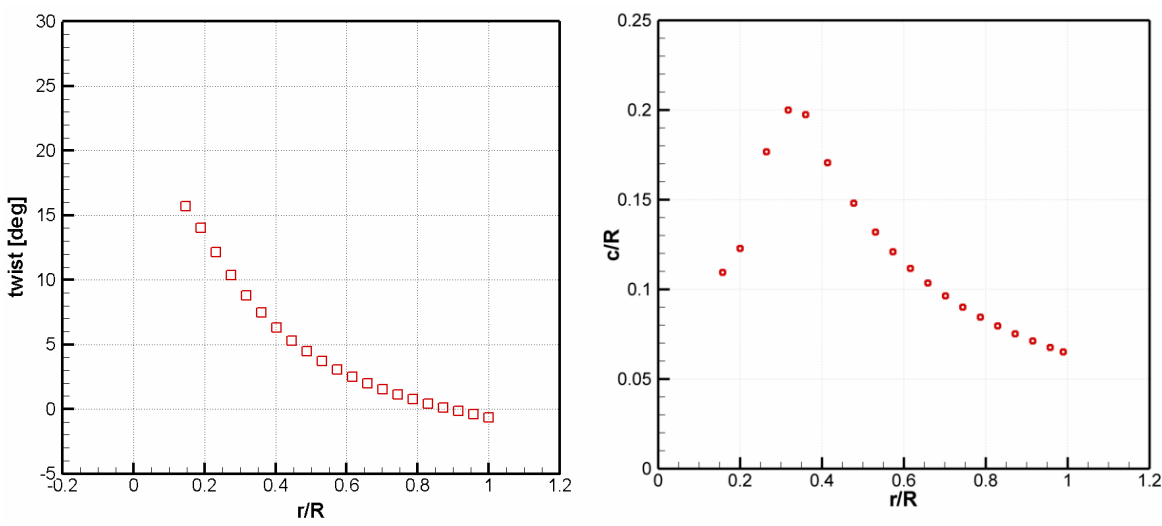

Figure 2 Twist and Chord distributions obtained from BEM optimization. 


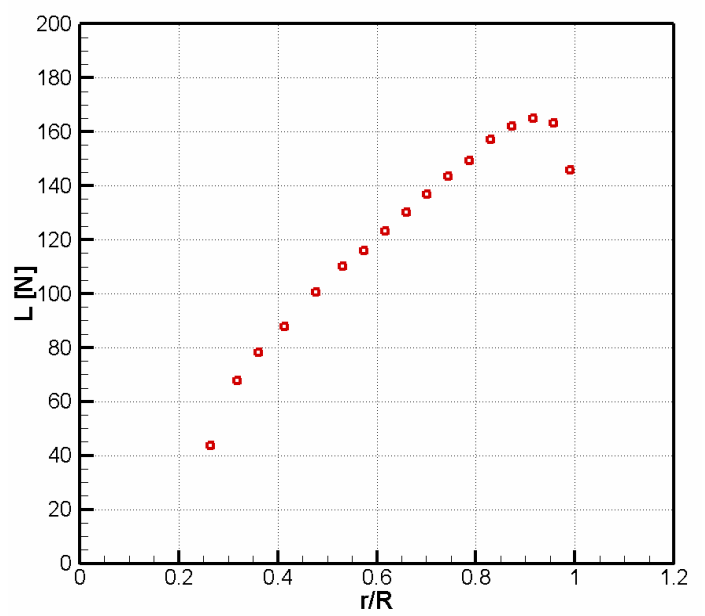

Figure 3 Lift distributions obtained from BEM calculations.

The blades are mounted into a new designed model rotor test bank (see Fig. 4). The speed of the rotor shaft is variable (from 0 to $20 \mathrm{~Hz}$ ) and it is controlled by a program. The maximum wind speed of the turbine model at $\lambda=7$ is $17 \mathrm{~m} / \mathrm{s}$.
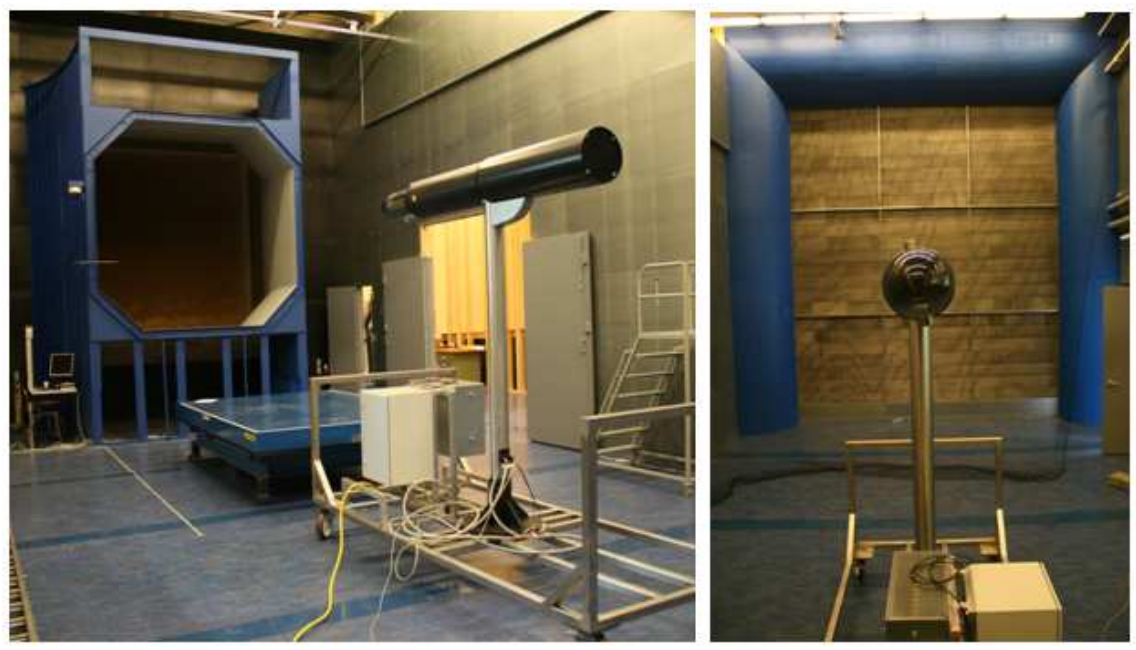

Figure 4 The new turbine model in OJF.

The Stereo PIV technique is applied to obtain the three components of velocity on the $2 \mathrm{D}$ planar fields of view around the blade. A group of optics is used to have a proper laser sheet. 16 mega pixel cameras with Nikon $\mathrm{f} 180 \mathrm{~mm}$ lenses and double cavity pulsed Nd:YAG laser were fixed on a computerized traverse system to move together (see Fig. 5, 6).

Synchronization between the laser pulses and the position of the rotating blade is required for the designed experiment. This is due not only to the need of assuring phase-lock data sets for the PIV analysis, but it is also required to reconstruct the volumetric flow field in the rotor plane and in the wake without the need of an azimuthal scanning. If indeed the axial symmetry of the flow field can be assumed as hypothesis; keeping the laser sheet at a fixed position in space and acquiring the data when the reference blade is at different azimuth positions is equivalent to an angular scan with the blade at a fixed position. The reason for this approach is an evident saving of time and costs. Since the model had no internal sensor to measure the position of the blade, a trigger device has been produced. 
Two different measurement setups are designed in the OJF to scan the flow field around the blade by stereo PIV (see Fig. 5, 6). The idea behind having two measurement sets in two directions (spanwise and chordwise) is to combine the results to have a solid structure of the flow field around the blade. 62 planes on the blade are investigated for chordwise measurements. As it is shown in Fig. 5, at the tip region the measurements were performed for every 5 $\mathrm{mm}$ and for every $20 \mathrm{~mm}$ on the blade. 154 azimuth planes on the blade are investigated for spanwise measurements. 4 spanwise measurement stations are defined to cover the whole blade. At each measurement stations different azimuth angles were investigated. As it is shown in Fig. 7, azimuth angles from $-5^{\circ}$ to $55^{\circ}$ with steps of $2^{\circ}$ for the first field of view, from $-5^{\circ}$ to $25^{\circ}$ with steps of $1^{\circ}$ for the second field of view, from $-5^{\circ}$ to $10^{\circ}$ with steps of $0.5^{\circ}$ for the third field of view and from $-5^{\circ}$ to $10^{\circ}$ with steps of $0.25^{\circ}$ for the fourth field of view were scanned. The selected angles assure to cover the entire blade.

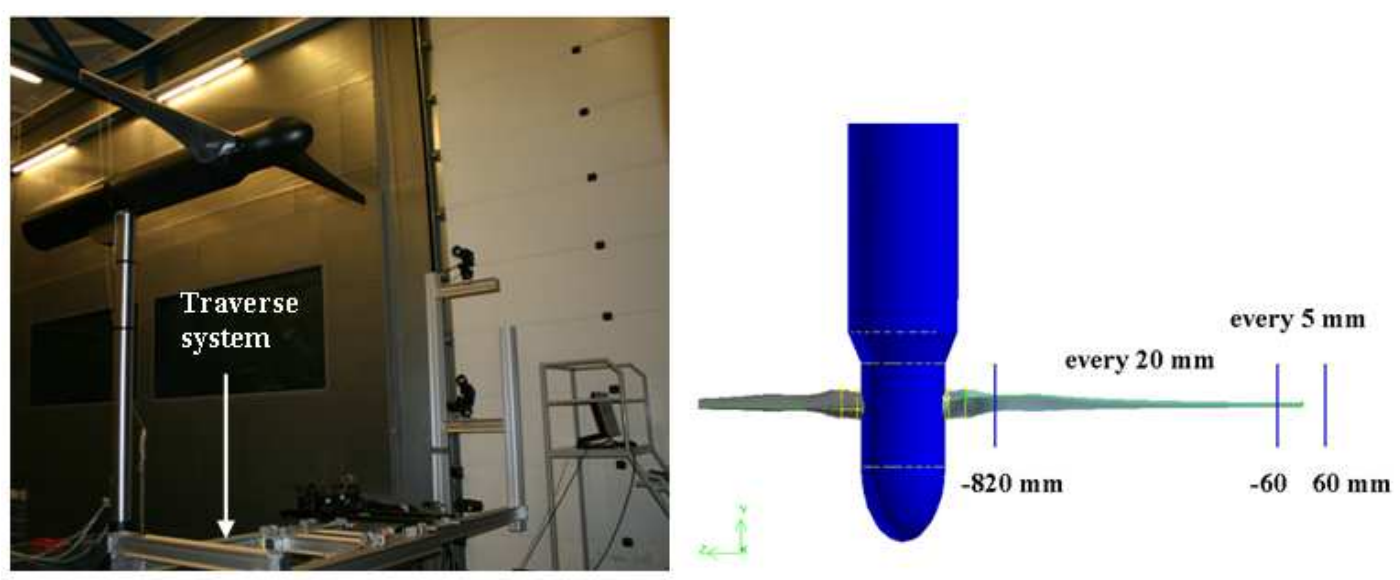

Figure 5 Chordwise measurement setup and measurement planes.

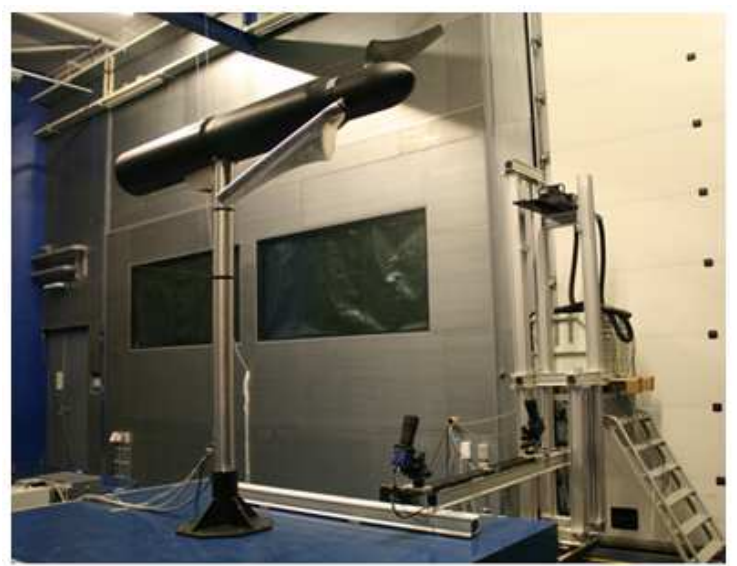

Figure 6 Spanwise measurement setup. 

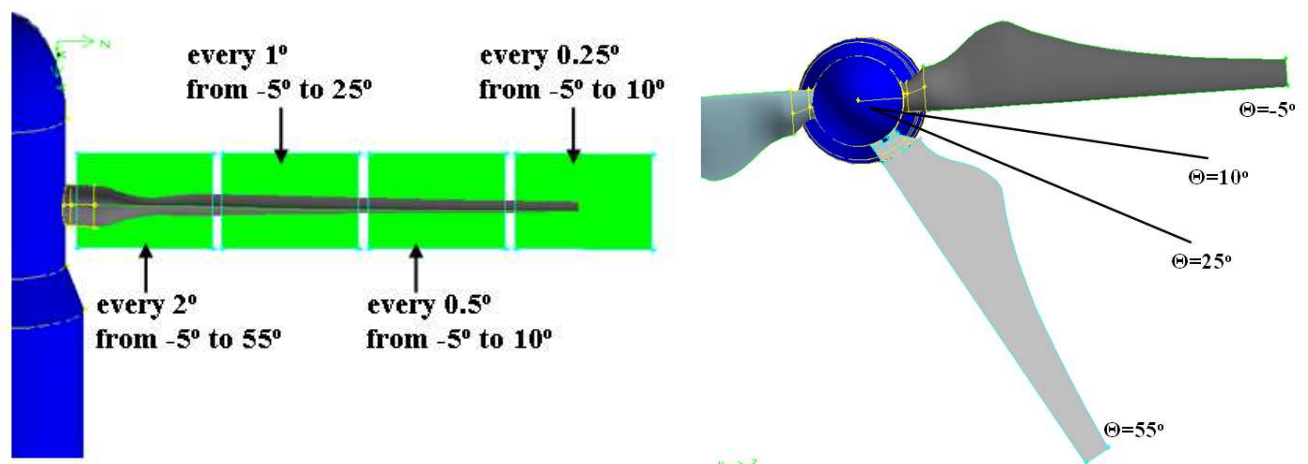

Figure 7 Schematic representations of the measurement planes and azimuth angles.

Measurement conditions and parameters are tabulated in Table 1. The images have been processed with a multistep refinement process of 5 passes with decreasing window size. The last windows size of 32 pixels with an overlap of $75 \%$ resulted in a final vector spacing of $0.504 \mathrm{~mm} \times 0.504 \mathrm{~mm}$. From the 30 phased-locked vector fields, average and RMS values of the three components of the velocity have been derived. These served as basis for the following data processing done with MATLAB codes, developed on purpose.

Table 1 Measurement conditions and parameters

\begin{tabular}{|c|c|c|}
\hline TSR & RPM & $\mathbf{U}_{\text {inf }}[\mathbf{m} / \mathbf{s}]$ \\
\hline 7 & 720 & 10.8 \\
\hline \hline \multicolumn{2}{|c|}{ FOV } & $\Delta \mathbf{T}$ \\
{$[$ pixels] } & {$[\mathbf{m m}]$} & {$[\boldsymbol{\mu s}]$} \\
\hline $4872 \times 3248$ & $316 \times 204$ & 60 \\
\hline
\end{tabular}

Measurements obtained from the spanwise set-up have been processed as mentioned above and represented in two planes. In Figure 8, spanwise velocity distribution is represented on different radial locations from $26 \%$ to $60 \%$ radius of the rotor. The pictures present the flow field on the suction side of the blade. Till $36 \%$ of the rotor, there is a decrease in spanwise velocity but after that location, it starts to increase on the suction side of the blade. The increase in spanwise velocity can be explained by increasing lift along the span (see Fig. 3). In Figure 9, spanwise velocity distribution is represented at different chordwise locations which are mentioned on the pictures presented in Fig. 8. One can observe the flow field on the suction side of the blade at different chord locations (from leading edge to trailing edge) on spanwise plane. As can be seen on both Fig. 8 and 9, the spanwise velocity has negative values at the root region close to leading edge. 

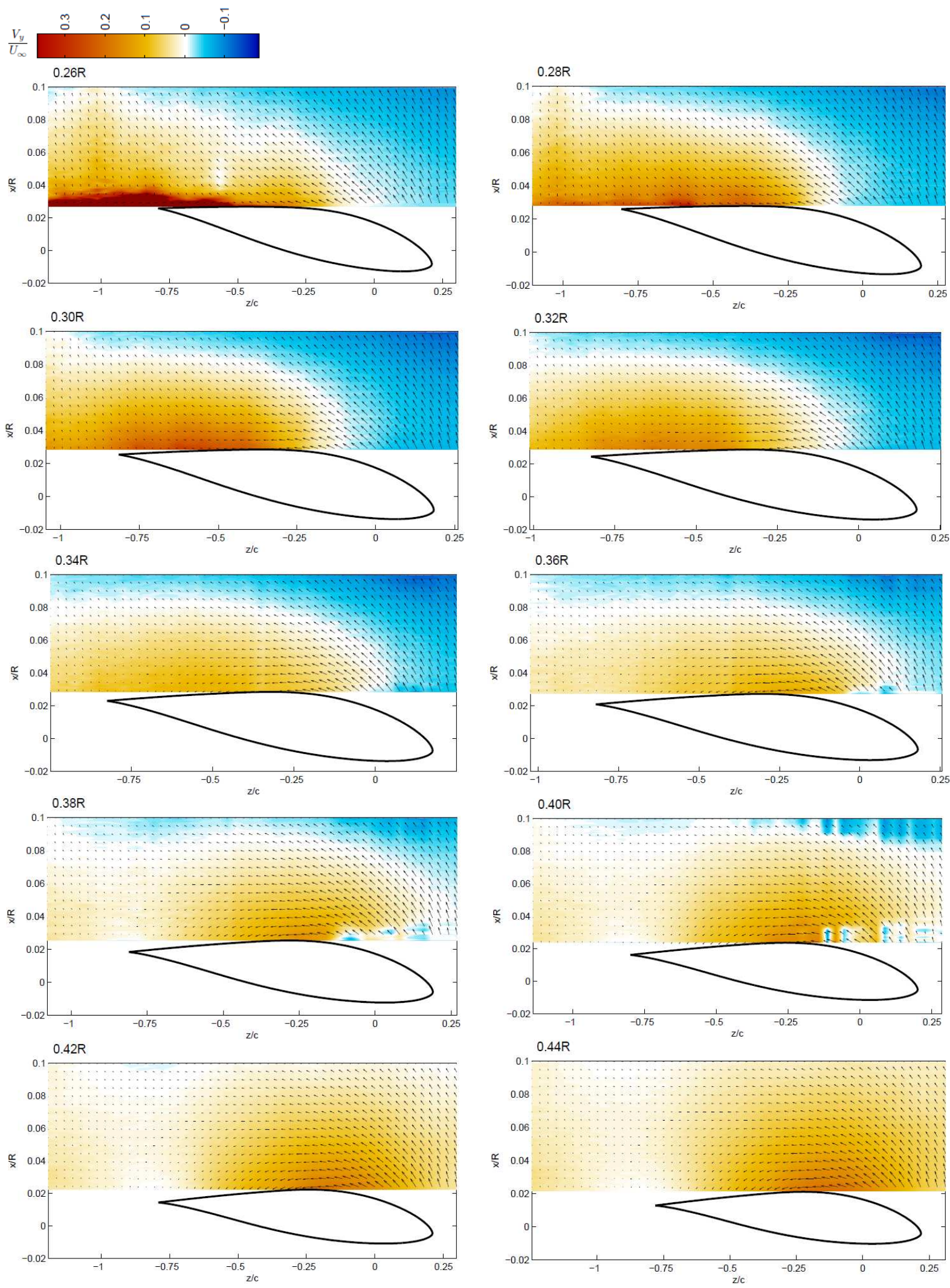

Figure 8 Spanwise velocity contours at different radial locations. 

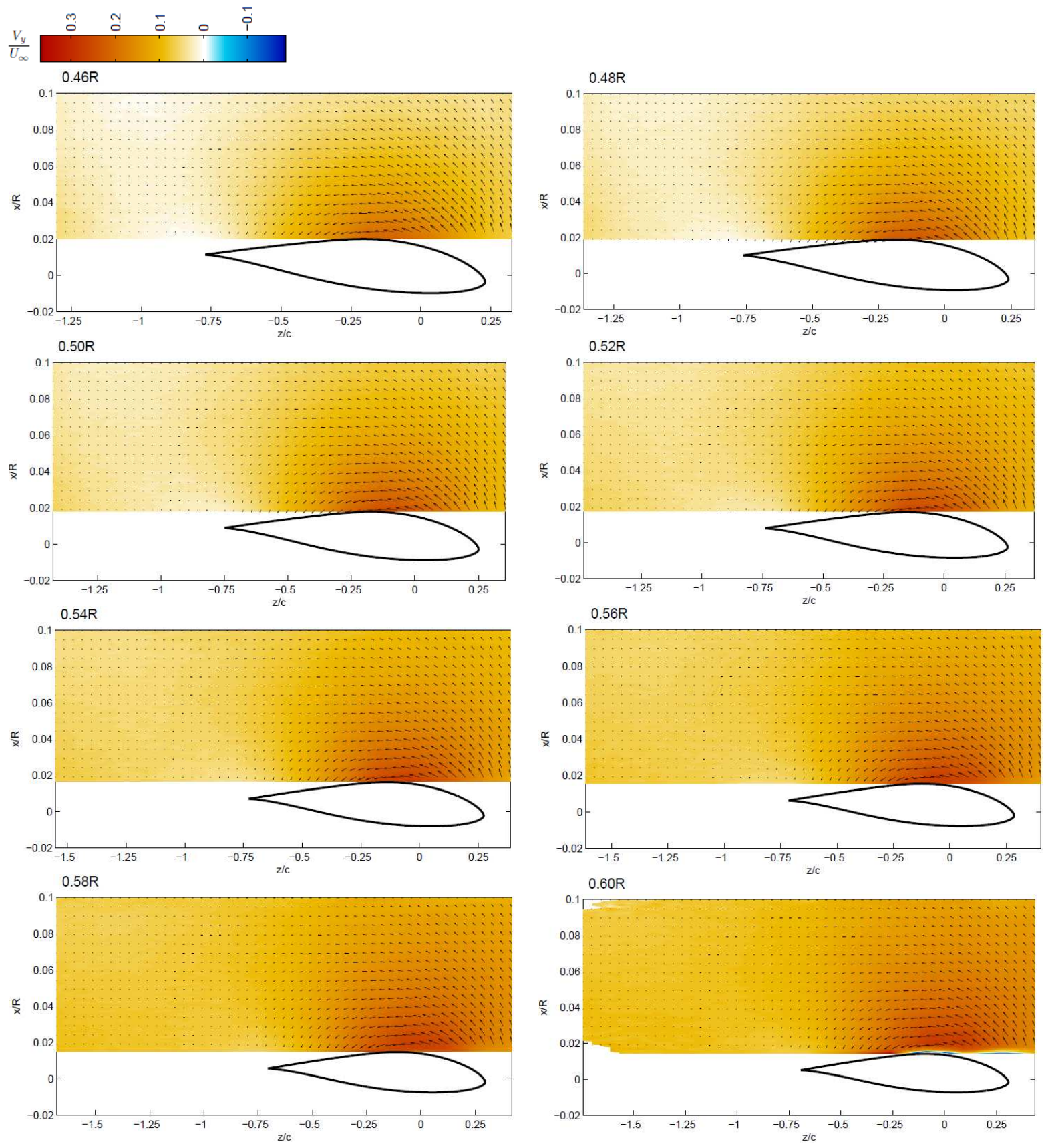

Figure 8 (Continued) Spanwise velocity contours at different radial locations. 

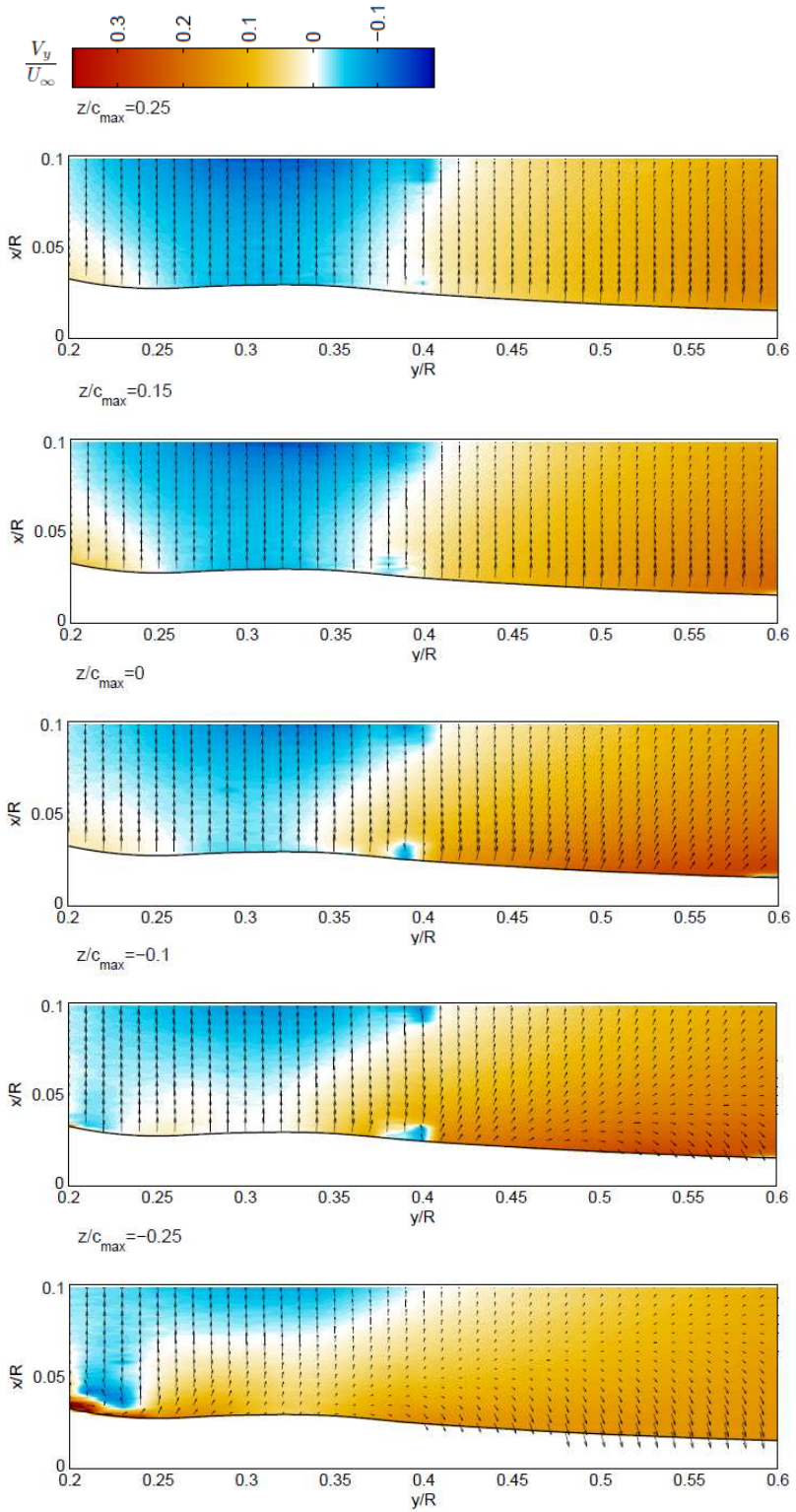

$\mathrm{z} / \mathrm{c}_{\max }=-0.35$
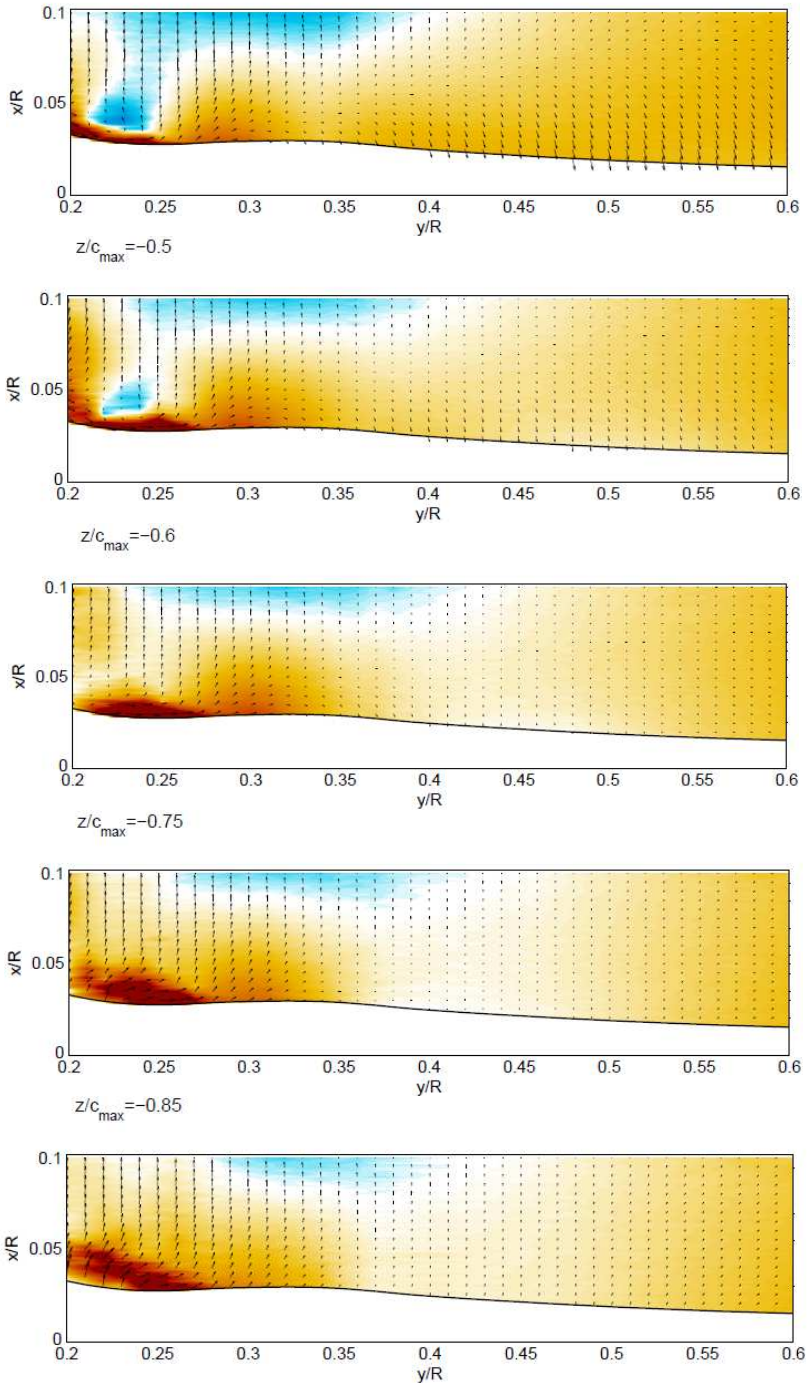

Figure 9 Spanwise velocity contours at different chordwise locations.

\section{Conclusions}

This paper represents the results of the experiments performed in Open Jet Facility by means of stereo PIV to visualize the flow structures around a $1 \mathrm{~m}$ radius 2 bladed rotor by focusing on root region.

The measurements have been performed on the suction side of the blade and not in the boundary layer. While spanwise velocity distribution shows a complex pattern in the root region, it has a smooth distribution in the spanwise direction beyond $\mathrm{r} / \mathrm{R}=0.4$ at the leading edge $(\mathrm{z} / \mathrm{c}=0.25)$. This smooth tendency in spanwise velocity increases and covers the blade as it goes to trailing edge $(z / c=-0.85)$. High spanwise velocity gradient is explained by the lift distribution along the span. Since this is only a preliminary phase of the work, the data need to be better investigated and discussed with the support of the next experiments. 


\section{Acknowledgments}

The present research project is sponsored by VESTAS.

\section{References}

${ }^{1}$ Johansen, J., Madsen, H. A., Sørensen, N. N. and Bak, C., "Numerical Investigation of a Wind Turbine Rotor with an Aerodynamically Redesigned Hub-region," European Wind Energy Conference (EWEC), 2006.

${ }^{2}$ Rauch, J., Kramer, T., Heinzelmann, B., Twele, J. and Thamsen, P.U., “3D Numerical Simulation and Evaluation of the Air Flow through Wind Turbine Rotors with Focus on the Hub Area," Wind Energy, pp. 227-230, 2007.

${ }^{3} \mathrm{Hu}$, D., Hua, O., and Du, Z., “A Study on Stall-delay for Horizontal Axis Wind Turbine,” Renewable Energy 31, pp. 821836, 2006.

${ }^{4}$ Dumitrescu, H. and Cardos, V., "Rotational Effects on the Boundary-Layer Flow in Wind Turbines," AIAA Journal Vol. 42, No: 2, Technical Notes, 2003.

${ }^{5}$ Schreck, S. J., Sørensen, N. N. and Robinson, M. C., “Aerodynamic Structures and Processes in Rotationally Augmented Flow Fields," Wind Energy, 10, pp. 159-178, 2007.

${ }^{6}$ Tangler, J. and Kocurek, J. D. "Wind Turbine Post-Stall Airfoil Performance Characteristics Guidelines for Blade-Element Momentum Methods," 43 ${ }^{\text {rd }}$ AIAA Aerospace Sciences Meeting and Exhibition Reno, Nevada, 2005.

${ }^{7}$ Tangler, J. L., “Insight into Wind Turbine Stall and Post-stall Aerodynamics,” Wind Energy, 7, pp. 247-260, 2004. 